\title{
Consolidation of Remote Fear Memories Involves Corticotropin-Releasing Hormone (CRH) Receptor Type I-Mediated Enhancement of AMPA Receptor GluR I Signaling in the Dentate Gyrus
}

\author{
Christoph K Thoeringer', Kathrin Henes', Matthias Eder', Maik Dahlhoff ${ }^{2}$, Wolfgang Wurst ${ }^{3}$, \\ Florian Holsboer', Jan M Deussing', Sven Moosmang ${ }^{4}$ and Carsten T Wotjak*,I \\ 'Max Planck Institute of Psychiatry, Munich, Germany; ${ }^{2}$ Institute of Molecular Animal Breeding and Biotechnology, Gene Center, LMU Munich, \\ Germany; ${ }^{3}$ Institute of Developmental Genetics, Helmholtz Zentrum Munich, Neuherberg, Germany; ${ }^{4}$ Institute of Pharmacology and Toxicology, \\ Technical University Munich, Munich, Germany
}

\begin{abstract}
Persistent dreadful memories and hyperarousal constitute prominent psychopathological features of posttraumatic stress disorder (PTSD). Here, we used a contextual fear conditioning paradigm to demonstrate that conditional genetic deletion of corticotropinreleasing hormone $(\mathrm{CRH})$ receptor I within the limbic forebrain in mice significantly reduced remote, but not recent, associative and non-associative fear memories. Per os treatment with the selective CRHRI antagonist DMP696 (3 mg/kg) attenuated consolidation of remote fear memories, without affecting their expression and retention. This could be achieved, if DMP696 was administered for I week starting as late as $24 \mathrm{~h}$ after foot shock. Furthermore, by combining electrophysiological recordings and western blot analyses, we demonstrate a delayed-onset and long-lasting increase in AMPA receptor (AMPAR) GluRI -mediated signaling in the dentate gyrus (DG) of the dorsal hippocampus I month after foot shock. These changes were absent from CRHRI-deficient mice and after DMP696 treatment. Inactivation of hippocampal GluRI-containing AMPARs by antisense oligonucleotides or philantotoxin 433 confirmed the behavioral relevance of AMPA-type glutamatergic neurotransmission in maintaining the high levels of remote fear in shocked mice with intact CRHRI signaling. We conclude that limbic CRHRI receptors enhance the consolidation of remote fear memories in the first week after foot shock by increasing the expression of $\mathrm{Ca}^{2+}{ }^{+}$-permeable GluRI-containing AMPARs in the DG. These findings suggest both receptors as rational targets for the prevention and therapy, respectively, of psychopathology associated with exaggerated fear memories, such as PTSD.

Neuropsychopharmacology (2012) 37, 787-796; doi:I0.1038/npp.20II.256; published online 26 October 20।I
\end{abstract}

Keywords: CRHRI; GluRI; PTSD; therapy; CRF; CRF receptor I

\section{INTRODUCTION}

Posttraumatic stress disorder (PTSD) is a severe and disabling psychiatric disease that is triggered by experience of a trauma. The life-time prevalence of experiencing a trauma-like incident is up to $75 \%$ for an individual (Yehuda and Ledoux, 2007), and up to $8 \%$ individuals of the general population develop the disease (Kessler et al, 1995). Pharmacotherapeutic strategies with PTSD-approved drugs, such as selective-serotonin reuptake inhibitors, achieve remission rates in only 66\% of patients (Albucher and Liberzon, 2002). This asks for the development of better

*Correspondence: Dr CT Wotjak, Max Planck Institute of Psychiatry, Kraepelinstr. 2-10, 80804 Munich, Germany, Tel: + 498930622 652, Fax: + 498930622 6I0, E-mail: wotjak@mpipsykl.mpg.de

Received 18 May 2011; revised 12 August 2011; accepted 2 September 2011 therapies, which requires a deeper understanding of the neurobiological mechanisms involved in the development of PTSD. However, only little is known about the neurobiology of the processes underlying the consolidation of remote fear memories (Cui et al, 2004; Frankland et al, 2004; Pastalkova et al, 2006). Moreover, some of the identified targets such as BDNF (Bekinschtein et al, 2007) are not readily accessible for pharmacological interventions in human patients. This explains the interest in the contribution of neuropeptides to the development and maintenance of PTSD (Ressler et al, 2011). Among them, corticotropin-releasing hormone (CRH) seems to be particularly promising. CRH was identified as the major component of the body's hormonal stress response (Vale et al, 1981). Along with this activation of the hypothalamuspituitary-adrenocortical (HPA) system, CRH controls anxiety responses in extrahypothalamic brain areas (Müller et al, 2003; Walker et al, 2003) through two G 
protein-coupled receptors, namely CRHR1 and CRHR2 (Bale and Vale, 2004). CRH signaling within the amygdala or the hippocampus has also been shown to affect acquisition and consolidation of recent fear memories (Kolber et al, 2008; Pitts et al, 2009; Radulovic et al, 1999; Roozendaal et al, 2002; Tovote et al, 2005), including the development of non-associative fear responses (Adamec et al, 2010). It is noteworthy that clinical data suggest an involvement of $\mathrm{CRH}$ in long-lasting psychopathological anxiety observed in PTSD (Bremner et al, 1997). However, the specific contribution of $\mathrm{CRH}$ to the development, expression, and/or retention of remote fear memories has not been explored in animal models of this disorder.

Therefore, this study assessed the role of CRH in consolidation of trauma-related fear in a mouse model of PTSD. This model involves exposure to a brief, but intense, electric foot shock and the subsequent assessment of associative (ie, contextual) and non-associative (ie, sensitized response to an a priori neutral tone) fear (Siegmund and Wotjak, 2007). This dichotomy refers to the different psychopathological components of PTSD: Associative learning accounts for intrusive memories and avoidance behavior, whereas non-associative (or stress-related) learning results in hyperarousal (Siegmund and Wotjak, 2006).

The first part of this study assessed whether CRH affects remote fear memories (ie, contextual and sensitized fear), and identified the CRH receptor subtype involved. This was achieved by testing different mutant mice lacking expression of CRHR1/CRHR2 either throughout the whole body or selectively within the brain/limbic forebrain 1 month after the foot shock. The second part dissected the involvement of CRHR1 signaling in consolidation $v s$ retention/expression of remote fear by pharmacological means. The third part dealt with potential effectors of CRHR1 signaling. In this context, we focused on AMPA receptor (AMPAR) trafficking, which has been repeatedly shown to underlie the consolidation of different types of aversive memories (Clem and Huganir, 2010; Hu et al, 2007; Mitsushima et al, 2011; Rumpel et al, 2005; Whitlock et al, 2006). However, these studies did not resolve whether remote fear memories in general, and the fear-promoting effects of limbic CRHR1 signaling in particular, involve long-term changes in AMPAR neurotransmission. We focused specifically on changes at level of the dentate gyrus (DG) as the entrance point of the hippocampus formation. Several lines of evidence suggest a crucial role for the DG in the formation of episodic memories by the process of pattern separation (Treves et al, 2008), which may involve neurogenesis in the subgranular zone (Sahay et al, 2011). The remote fear responses observed in our animal model largely resemble fear generalization, most probably on the basis of impaired context discrimination, ie, pattern separation (Golub et al, 2009; Pamplona et al, 2011). Interestingly, excessive fear generalization is considered a main feature of PTSD (Peri et al, 2000).

Our experiments revealed a scenario, according to which exposure to an intense, aversive foot shock leads to a transient activation of CRHR1 signaling within the limbic forebrain within the first week after traumatic incident that enhances the consolidation and retention of remote fear memories by increased expression of $\mathrm{Ca}^{2+}$-permeable GluR1containing AMPARs at the level of the dorsal hippocampus.

\section{MATERIALS AND METHODS}

\section{Mice}

Experiments were performed with male mice at an age of 817 weeks. On arrival at the animal facility of the Max Planck Institute of Psychiatry, all mice were kept under standardized, single housing conditions (ie, Makrolon type II cages with wood shavings, inverse $12: 12 \mathrm{~h}$ light-dark schedule with lights off at 0900 hours, at $22 \pm 2{ }^{\circ} \mathrm{C}$ room temperature and $55 \pm 5 \%$ humidity). Water and food were provided $a d$ libitum. Animals were allowed to habituate to the housing conditions for 2 weeks before starting the experiment.

C57BL/6N mice. C57BL/6NCrl inbred mice were purchased from Charles River Germany at an age of 6-7 weeks.

Mouse mutants. All mutant mice (KO) and their respective wild-type (WT) littermate controls were generated in our local breeding facilities (MPIP, MPIBC) and genotyped as described previously (Total CRHR1 (ie, R1-KO/WT; Timpl et al (1998)); CRHR1 ${ }^{\text {loxPlloxP;Nes-Cre }}$ (ie, $\mathrm{R}^{\text {Nes }}$-KO/WT; Schmidt et al

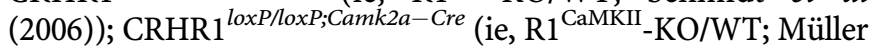
et al (2003)); Total CRHR2 (ie, R2-KO; Coste et al (2000)). Mice were kept at different genetic backgrounds (R1-KO/WT: 129S2/SvPas x CD1: R1 ${ }^{\mathrm{Nes}}-\mathrm{KO} / \mathrm{WT}$ and $\mathrm{R} 1^{\mathrm{CaMKII}}-\mathrm{KO} / \mathrm{WT}$ : 129S2/SvPas x C57BL/6J; R2-KO/WT: C57BL/6J Mice). R1$\mathrm{KO} / \mathrm{WT}$ and $\mathrm{R} 2-\mathrm{KO} / \mathrm{WT}$ were derived from heterozygous breeding pairs. In case of the $\mathrm{R} 1^{\mathrm{CaMKII}}$ line, mutants were maintained by breeding pairs with the genotypes Cre();CRHR1 ${ }^{\text {loxP/loxP }}$ (ie, WT) for the father and Cre(+ );CRHR $1^{\text {loxP/loxP }}$ (ie, KO) for the mother to avoid germline recombination, which is frequently encountered in males of this line. In case of the $\mathrm{R} 1^{\mathrm{Nes}}$ line, the arrangement of the breeding pairs was vice versa. R1-KO and R2-KO lack expression of CRHR1 and CRHR2, respectively, throughout the entire body (ie, including the anterior pituitary). As a consequence, stress-induced release of the adrenocorticotrope hormone and corticosterone is reduced in R1-KO mice, whereas basal steroid release is not affected. In contrast, in $\mathrm{R} 1^{\text {Nes }}-\mathrm{KO}$, deletion of CRHR 1 expression is restricted to the brain, ie, to all neurons/glia cells, but not the anterior pituitary, thus sparing the key regulatory brain center of the HPA axis. R1 ${ }^{\text {CaMKII }}$-KO lack expression of CRHR1 in telencephalic and limbic brain structures, but not in the hypothalamus (and in the pituitary). Thus, basal or stress-induced activation of HPA axis remains unaffected in these mice (Müller et al, 2003).

All experimental procedures were approved by the Committee on Animal Health and Care of the local government (ie, Regierung von Oberbayern) and performed in accordance with the guidelines for the care and use of laboratory animals set by the European Community Council (86/609/CEE).

\section{Foot Shock Delivery and Testing Procedures}

Experimental set-ups and procedures have been previously described in detail (Kamprath and Wotjak, 2004; Siegmund and Wotjak, 2007). In brief, experiments were performed in two different contexts: Foot shock application and testing for conditioned contextual fear were performed in a mouseconditioning chamber that has a cubic shape with two metal and two Plexiglas walls and a metal grid floor. Sensitized fear was assessed in a neutral context consisting of a 
Plexiglas cylinder with wood shavings as bedding. Both contexts were cleaned with detergents of different odors (conditioning chamber: $70 \%$ ethanol; neutral context: $1 \%$ acetic acid).

For application of foot shock (day 0), animals were placed into the conditioning chamber, and after $198 \mathrm{~s}$, a scrambled electric foot shock ( $2 \mathrm{~s}$ duration, $1.5 \mathrm{~mA}$ current intensity) was delivered through the metal grid. Animals remained in the conditioning chamber for an additional $60 \mathrm{~s}$ before they were returned to their home cages. Assessing sensitized (ie, non-associative) fear, mice were placed in the neutral test context, and after $180 \mathrm{~s}$, a 3 -min neutral tone $(80 \mathrm{~dB}, 9 \mathrm{kHz})$ was presented to the animals. Contextual (ie, associative) fear was tested by re-exposing animals to the conditioning chamber for $3 \mathrm{~min}$. In general, testing for recent or remote fear memories was performed either within 1-3 (recent fear) or within 28-30 days (remote fear) after delivery of the foot shock. The differences in time points are related to different experimental interventions (eg, intrahippocampal injections) before testing (for details, see figures and figure legends).

As a measure of fear, we assessed freezing behavior defined as the absence of all movements except for respiration and the animal's head remaining in a horizontal position. Freezing behavior was recorded and analyzed offline by an observer blind to genotype or treatment.

\section{Oral Drug Administration}

We administered the specific CRHR1 antagonist DMP696 (kindly provided by Bristol Myers Squibb) orally because of its good pharmacokinetic characteristics (Li et al, 2003). The drug was dissolved in saccharose-flavored $\mathrm{NaCl} 0.9 \%$ containing 10\% DMSO, 10\% PEG 400, and Tween-80 (1 drop/ml). Drug suspension was delivered on an oat flake and then fed to animals at a final dose of $3 \mathrm{mg} / \mathrm{kg}$. Controls received an oat flake soaked with saccharose-flavored vehicle only. The dose of $3 \mathrm{mg} / \mathrm{kg}$ was chosen on the basis of pilot experiments in which doses of 3,10 , and $30 \mathrm{mg} / \mathrm{kg}$ had been compared. The drug solutions were always freshly pipetted onto the flake and shortly dried before delivery. Ad libitum-fed mice received some saccharose-flavored oat flakes 2 days before starting an experiment to habituate them to the novel food. Over the course of treatment, mice showed no signs of aversion against the drug-soaked flakes, but readily ate them within a few seconds after delivery.

\section{Intrahippocampal Treatment}

Surgery. Mice were anesthetized with isoflurane (Forene, Abbott, Germany) and placed in a stereotaxic apparatus (TSE Systems, Germany) with adapted components to allow mouse inhalation anesthesia. After exposure of the skull, a hole was drilled and guide cannulae (23G) was implanted bilaterally in the dorsal hippocampus. Coordinates based on the stereotaxic mouse brain atlas (Franklin and Paxinos, 2001) were $-1.8 \mathrm{~mm}$ posterior to the bregma, $\pm 1.3 \mathrm{~mm}$ lateral from midline, and $1.0 \mathrm{~mm}$ below the surface of the skull. Cannulae were fixed to the skull with dental cement and two jeweler screws inserted into the skull. Mice received analgesic treatment before surgery $(0.5 \mathrm{mg} / \mathrm{kg}$ meloxicam s.c., Metacam, Boehringer Ingelheim, Germany) and 3 days afterwards through the drinking water at the same dose. Animals were allowed to recover from surgery for 2 weeks before starting the experiment.

Group assignment. Mice equipped with the guide cannulae received the electric foot shock as described earlier. To ensure equal levels of sensitization between the different groups before treatment with the AMPAR antagonists, we measured sensitized fear in response to a neutral tone essentially as described, except for the duration of the tone ( $1 \mathrm{~min}$ instead of $3 \mathrm{~min}$ ) either on day 2 or on day 28 after conditioning. Animals were assigned to treatment and control groups on the basis of their freezing responses to the tone in a manner that all the groups showed the same level of sensitized fear before treatment (data not shown).

Intracerebral injections. Mice were slightly anaesthetized with isoflurane, and drugs were infused into the hippocampus (i.h.) in a volume of $0.5 \mu$ (receptor antagonists) or $1 \mu \mathrm{l}$ (antisense oligonucleotides (ASOs)) per injection site over the course of 1-2 min. Injections were performed by means of an injection cannula, which was connected to a microliter syringe using a calibrated tubing containing an air bubble for monitoring treatment progress. The injection cannula protruded from the guide cannula by $1 \mathrm{~mm}$, thus reaching the stratum lacunosum moleculare of the dorsal hippocampus. After completion of the injection, it was left in place for another minute before removal. Mice were excluded from the experiment, if fluid/blood was flowing out of the guide cannula.

Drugs. AMPAR signaling was attenuated/blocked either by the unspecific AMPA/kainate receptor antagonist NBQX (2,3-dioxo-6-nitro-1,2,3,4-tetrahydrobenzo-quinoxaline-7sulfonamide disodium salt; $50 \mu \mathrm{M}$; Tocris Bioscience, Germany) or by philanthotoxin 433, a specific blocker of AMPARs containing the $\mathrm{Ca}^{2+}$-permeable GluR1, but not the $\mathrm{Ca}^{2+}$-impermeable GluR2 subunit $(100 \mu \mathrm{M}$; Sigma-Aldrich, Germany). In both cases, Ringer's solution served as vehicle control (Fresenius-Kabi, Germany), and injections were performed $30 \mathrm{~min}$ before measuring contextual fear 29 days after foot shock. A third batch of mice was infused with GluR1 antisense (ASO; $5 \mu \mathrm{M} ; 1 \mu$ infusion volume per side) or missense (MSO) oligonucleotides (dissolved in Ringer's solution) 3 times (12-h intervals) before testing for contextual fear memory on day 30 after foot shock administration (without previous tone testing on day 28). Oligonucleotides (Metabion International, Germany) were HPLC-purified 19-mer sequences with phosphorothioate bonds at both $5^{\prime}$ and $3^{\prime}$ ends: GluR1 ASO, 5'-TAAGCAT CACGTAAGGATC-3', GluR1 MSO， 5'-AGCGTATCACAG TATAGAC-3'. GluR1 ASO was screened in public libraries and proven to be specific for mouse Glur1 mRNA (Slipczuk et al, 2009), whereas control MSO sequences did not generate any full matches to identified gene sequences.

Histology. After each experiment, animals were killed with an overdose of isoflurane. Brains were removed, frozen in pre-chilled 2-methylbutane on dry ice, and stored at $-80^{\circ} \mathrm{C}$ until sectioning in a cryostat microtome. Correct placement of the injection sites within the dorsal hippocampus was assessed in the cryostat unaware of the treatment. This direct assessment enabled us to punch out the DG of ASO/MSO-treated mice for subsequent western blot analysis of GluR1 content in addition to histological 
verification of the injection sites. Only data of mice with correct bilateral hippocampal injections were included in further analyses.

\section{Electrophysiology}

Brain slice preparation. Acute hippocampal slices were prepared from 12-to-14-week-old male C57BL/6N mice and 8-15-week-old male $\mathrm{R}^{\mathrm{CaMKII}} \mathrm{KO} / \mathrm{WT} 28$ days after conditioning or control exposure to the conditioning chamber without shock delivery. Coronal slices $(350-\mu \mathrm{m}$ thick) were prepared using a vibratome (HM650V, Thermo Scientific) and maintained in artificial cerebrospinal fluid (aCSF) containing (in $\mathrm{mM}$ ) $125 \mathrm{NaCl}, 2.5 \mathrm{KCl}, 1.25$ $\mathrm{NaH}_{2} \mathrm{PO}_{4}, 25$ glucose, $25 \mathrm{NaHCO}_{3}, 1 \mathrm{MgCl}_{2}, 2 \mathrm{CaCl}_{2}$ at $\mathrm{pH}$ 7.4 saturated with $5 \% \mathrm{CO}_{2} / 95 \% \mathrm{O}_{2}$. Slices were allowed to recover in a storage chamber initially at $34{ }^{\circ} \mathrm{C}$ for $45 \mathrm{~min}$ and then at room temperature $\left(23-25^{\circ} \mathrm{C}\right)$ for another $30 \mathrm{~min}$ to $1 \mathrm{~h}$ before being transferred to the recording chamber.

AMPAR-MEPSC recording. Whole-cell patch-clamp recordings were carried out from granule cells of the DG in hippocampal brain slices using a SEC-10LX amplifier (NPI Electronics, Tamm, Germany). An infrared videomicroscope equipped with the gradient contrast system was used to visualize the somata of DG neurons. Whole-cell pipette internal solutions contained (in $\mathrm{mM}$ ) $130 \mathrm{CH}_{3} \mathrm{O}_{3} \mathrm{SCs}, 5 \mathrm{CsCl}$, 0.5 EGTA, 2 mg-ATP, 10 HEPES, and 5 glucose at pH 7.4adjusted with $\mathrm{CsOH}$. Patch-clamp electrodes (open-tip resistance of 4-6 M 2 ) were pulled from borosilicate glass capillaries (Harvard Apparatus, Kent, UK) on a DMZUniversal puller. Neurons were voltage clamped at $-60 \mathrm{mV}$, and AMPAR-mEPSCs were measured while slices were continuously superfused with oxygenated aCSF containing $1 \mu \mathrm{M}$ tetrodotoxin (TTX), $50 \mu \mathrm{M} \mathrm{D}(-)$-2-amino-5-phosphonopentanoic acid (AP5) and $10 \mu \mathrm{M}(-)$-bicuculline methiodide (BIM). All recordings were performed at room temperature.

AMPAR-mEPSCs were recorded in individual neurons during a $5 \mathrm{~min}$ period $5 \mathrm{~min}$ after breaking into the cell. Amplitudes and frequencies of AMPAR-mEPSCs were analyzed offline using the Mini Analysis software (Synaptosoft, GA) with a detection threshold set at $4 \mathrm{pA}$.

Chemicals for aCSF preparation were purchased from Merck (Germany), TTX and AP5 from Ascent Scientific (UK), and BIM from Tocris Biosciences (UK).

\section{Western Blot Analysis of AMPAR GluR1 Subunits}

$D G$ specimens. The amounts of total and synaptosomal AMPAR subunit GluR1 or GluR2 were determined in the tissue of hippocampal DG in non-shocked $v s$ shocked mice. Mice were killed under isoflurane anesthesia, and brains were removed, frozen in pre-chilled methylbutane on dry ice, and stored at $-80^{\circ} \mathrm{C}$. Frozen brains were sectioned at $-20^{\circ} \mathrm{C}$ in a cryostat microtome, and DG tissue of the dorsal hippocampus was dissected bilaterally using cylindrical punchers (Fine Science Tools, Heidelberg, Germany; Dahlhoff et al (2010)) with internal diameters of $0.6 \mathrm{~mm}$. Specimens had a punch length of $\sim 1.0 \mathrm{~mm}$. The dissection site was verified by histological analysis.
Total GluR1 and GluR2. The punched hippocampal tissue of two brains was pooled and suspended in $60 \mu \mathrm{l}$ lysis buffer (50 mM Tris- $\mathrm{HCl}, 2 \%$ SDS, $\mathrm{pH} 7.5$ ), heated at $95^{\circ} \mathrm{C}$ for $10 \mathrm{~min}$ and further centrifuged at 12000 r.p.m. for $8 \mathrm{~min}$ at $4{ }^{\circ} \mathrm{C}$. The supernatant was transferred to a novel vial and stored at $-80^{\circ} \mathrm{C}$ until western blot analysis (see below).

Synaptosomal GluR1. Synaptosomal membrane preparation was performed with pooled punches of two brains. Tissue was homogenized on ice in $250 \mu \mathrm{l}$ lysis buffer $(0.5 \mathrm{M}$ EDTA, 1 M Tris-HCl, pH 7.4, 10 mM PMSF, 0.08\% Calpain I, $0.08 \%$ Calpain II, and a cocktail of protease inhibitors (Complete Protease Inhibitor Cocktail, Roche Applied Science, Germany)) and further centrifuged at 3000 r.p.m. for $4 \mathrm{~min}$. The supernatant was transferred to a novel vial and centrifuged at $70000 \times g$ for $35 \mathrm{~min}$ at $4{ }^{\circ} \mathrm{C}$. The membrane pellets were re-suspended in lysis buffer and stored at $-80^{\circ} \mathrm{C}$.

Immunoblotting. Samples were loaded onto SDS-PAGE gels (10\%) after normalization of protein concentrations for each sample (measurement of BSA equivalents by a NanoDrop spectrophotometer; Thermo Fisher Scientific, Germany). The resulting gels were transferred to PVDF membranes (Immobilion-P, Millipore, Germany). The membranes were then blocked with $3 \%$ BSA and $1 \%$ Tween-20 in PBS overnight at $4{ }^{\circ} \mathrm{C}$, incubated for $90 \mathrm{~min}$ with anti-GluR1 (1:100; anti-GluR1 pAB, Calbiochem, Germany) or anti-GluR2 (1:1000; anti-GluR2 (extracellular), Alomone Labs, Israel) or the p44/42-MAPK antibody (1:1000; Cell Signaling Technology, MA). The antibodies were dissolved in a buffer containing 1\% Tween-20, 5\% BSA, and $0.05 \% \mathrm{NaN}_{3}$ in PBS. Membranes were further washed three times for 10 min with $1 \%$ milk powder and $1 \%$ Tween-20 in PBS, and incubated for $1 \mathrm{~h}$ with peroxidaseconjugated anti-rabbit immunoglobulin (1:50 000 in blocking buffer; Dianova, Germany). After washing with $1 \%$ milk powder and $1 \%$ Tween-20 in PBS $(2 \mathrm{~min} \times 5 \mathrm{~min})$ and $1 \%$ Tween-20 in PBS $(1 \mathrm{~min} \times 10 \mathrm{~min})$, the membranes were immersed in chemiluminescence substrate (ECL; Western Lightning Chemiluminescence, Perkin-Elmer, Germany) for $1 \mathrm{~min}$ and then scanned in a Curix 60 scanner (Agfa, Germany). The scanned digital images were quantified using Adobe Photoshop 7.0 software by an investigator unaware of the source of specimens. We analyzed the relative amount of GluR1 (or GluR2) by determining the ratio of the signals detected by GluR1 (GluR2) and the p44/ 42-MAPK antibodies. In any of the western blot experiments, we did never observe differences in p44/42-MAPK levels between the experimental groups (data not shown).

\section{Data Analysis and Statistics}

Data are presented as mean \pm SEM. Behavioral data were averaged to the 3-min testing period and presented as a percentage of the analysis interval. To improve comparability of the data obtained in the different mutant lines (which were kept on different genetic backgrounds) and the experiments with pharmacological treatment, freezing data were expressed as a percentage of the means of the respective controls. Non-normalized data and sample sizes are reported in text or figures. Data were analyzed by two-group comparisons using unpaired Student's $t$-tests and one-sample $t$-tests to the basis $100 \%$ (if data were 
expressed relative to the mean control levels) as indicated in the 'Results' section and in figure legends. Analyses were performed using GraphPad Prism 5.0 (GraphPad, CA), Statistica 5.0 (StatSoft, OK), and SPSS 16.0 (SPSS, IL). Statistical significance was accepted if $p \leqslant 0.05$.

\section{RESULTS}

\section{CRHR1 in the Limbic Forebrain Enhances Remote Fear Memories}

We exposed mice with constitutive genetic deletions of either CRHR1 (R1 KO) or CRHR2 (R2 KO) to an electric foot shock and tested them for freezing to a neutral tone in a neutral context as a measure of sensitized fear and to the shock context as a measure of contextual fear 28 days later. R1 KO showed significantly reduced sensitized fear $\left(t_{22}=2.4 ; p=0.023\right)$, but no significant differences in contextual fear $\left(t_{22}=1.4 ; p=0.134 ; \mathrm{WT}\right.$ control freezing tone: $50.2 \pm 7.7 \%$, context: $44.7 \pm 8.5 \%)$. Changes in fear responses were observed in $\mathrm{R} 2 \mathrm{KO}$ only with respect to an increase in contextual fear (Figure 1a; tone: $t_{23}=0.6$; $p=0.549$; context: $t_{23}=1.7 ; p=0.045$; WT control freezing tone: $64.3 \pm 3.0 \%$, context: $73.4 \pm 6.2 \%$ ).

R1 KO mice lack expression of the receptor also at the level of the pituitary with the consequence of an impaired HPA axis activity (Timpl et al, 1998). To rule out that this deficiency accounts for reduction in remote sensitized fear, we tested conditional CRHR1 mutants with undisturbed HPA axis activity because of restriction of CRHR1 deletion to the brain $\left(\mathrm{R} 1^{\mathrm{Nes}}\right)$ or specifically to the forebrain $\left(\mathrm{R} 1^{\text {CaMKII }}\right)$. Both $\mathrm{R} 1^{\text {Nes }}$ and $\mathrm{R} 1^{\text {CaMKII }} \mathrm{KO}$ mice showed significantly reduced sensitized $\left(\mathrm{R} 1^{\mathrm{Nes}}: t_{20}=2.5 ; p=0.022\right.$; $\left.\mathrm{R} 1^{\mathrm{CaMKII}}: t_{25}=2.6 ; p=0.015\right)$ and contextual fear $\left(\mathrm{R} 1^{\mathrm{Nes}}\right.$ :

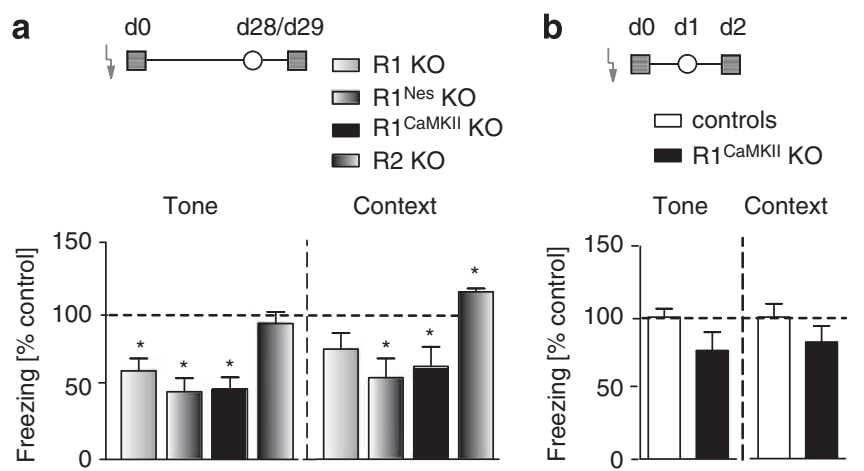

Figure I Limbic CRHRI signaling promotes long-term consolidation of sensitized and contextual fear. (a) Conventional (RI KO) and, in particular, conditional CRHRI knockouts (Cre-induced brain-specific (Nestin promoter, $\mathrm{RI}^{\mathrm{Nes}} \mathrm{KO}$ ) and forebrain-specific (CaMKII promoter, RI CaMKII $\mathrm{KO}$ ) CRHRI deletions), but not conventional CRHR2 knockouts (R2 KO), show reduced freezing to a 3-min tone in a novel context $(\mathrm{O})$ and to the shock context (回) 28 and 29 days after exposure to an un-signaled electric foot shock (I.5 mA, $2 \mathrm{~s}$; เ $16,\left.R\right|^{\mathrm{Nes}}=10 / 12,\left.R\right|^{\mathrm{CaMK} \mid 1}=\mid 4 / 13$, and $R 2=13 / \mid 2$. For the sake of clarity, freezing levels were expressed as a percentage of the means of the respective wild-type controls. (b) Genotype differences of R/ ${ }^{\mathrm{CaMKII}}$ mice in freezing to tone and context were not significantly reduced, if animals were tested $I-2$ days after foot shock. $n($ control/KO) $=16 / 14$. * $p<0.05$ (onesample $t$-test) $\left.t_{19}=2.2 ; p=0.019 ; \mathrm{R}^{\mathrm{CaMKII}}: t_{23}=1.7 ; p=0.050\right) 4$ weeks after conditioning (Figure $1 \mathrm{a} ; \mathrm{R} 1^{\mathrm{Nes}} \mathrm{WT}$ control freezing tone: $41.1 \pm 8.5 \%$, context: $41.8 \pm 5.6 \%$; R1 ${ }^{\text {CaMKII }}$ WT control freezing tone: $29.7 \pm 5.2 \%$, context: $40.4 \pm 7.5 \%$ ).

Sensitized and contextual fear were not significantly reduced in $\mathrm{R} 1{ }^{\mathrm{CaMKII}} \mathrm{KO}$ (tone: $t_{29}=1.7 ; p=0.092$; context: $\left.t_{28}=1.2 ; p=0.240\right)$, if mice were tested 1 and 2 days after conditioning (Figure $1 \mathrm{~b} ; \mathrm{R} 1^{\mathrm{CaMKII}}$ WT control freezing tone: $55.9 \pm 3.4 \%$, context: $63.7 \pm 6.0 \%)$.

Taken together, our data obtained in $\mathrm{R} 1^{\text {CaMKII }}$ mice indicate that remote fear memories are potentiated by CRHR1 signaling within the limbic forebrain.

\section{The CRHR1 Receptor Antagonist DMP696 Attenuates Development of Remote Fear Memories}

Studies in mutant mice preclude a more detailed dissection of $\mathrm{CRH}$ effects in terms of early $v s$ late consolidation, retention or expression of remote fear memories. Therefore, we treated $\mathrm{C} 57 \mathrm{BL} / 6 \mathrm{~N}$ mice with the specific CRHR1 antagonist DMP696 (3 mg/kg; p.o., twice daily) at different time points after foot shock: Acute administration of DMP696 $1 \mathrm{~h}$ before testing did not affect the expression of sensitized fear 28 days after trauma (treatment group I, Figure $2 ; t_{23}=0.0 ; p=0.987 ;$ control freezing tone: $31.9 \pm 7.2 \%)$. In contrast, administration of DMP696 for 1 week starting either immediately (group II) or $24 \mathrm{~h}$ after foot shock delivery (group III) resulted in a significant reduction of remote, trauma-related fear as assessed 21 days later (Figure 2; II, tone: $t_{25}=2.4 ; p=0.022$; III, tone: $t_{25}=2.3 ; p=0.033 ;$ II, context: $t_{25}=2.3 ; p=0.031$; III, context: $t_{25}=2.2 ; p=0.038$; group II and III control freezing tone: $45.5 \pm 5.7 \%$, context: $58.2 \pm 5.3 \%$ ). Once long-term consolidation of remote fear memories was established, memory retention was unaffected by CRHR1, as treatment with DMP696 over the course of 2 weeks, starting 28 days after foot shock, followed by an additional week of drug wash out, had no influence on sensitized and contextual fear (Figure 2; IV, tone: $t_{30}=0.1 ; p=0.902$; context: $t_{30}=0.1$; $p=0.904$; control freezing tone: $63.7 \pm 6.2 \%$, context: $82.1 \pm 2.1 \%)$.

\section{AMPAR Trafficking is Associated with the Development of Remote Fear Memories}

In vitro patch-clamp recordings of AMPAR-mediated miniature excitatory postsynaptic currents (AMPAR-mEPSCs) revealed significantly increased amplitudes, but not frequencies, of AMPAR-mEPSCs in DG granule cells of C57BL/6N mice 28 days after foot shock (Figure $3 \mathrm{a}$; amplitude: $t_{47}=2.2$; $p=0.032$; frequency: $t_{47}=1.1 ; p=0.295$; resting membrane potentials (RMPs): $53.3 \pm 1.8 \mathrm{mV}$ in shocked and $56.1 \pm 1.6 \mathrm{mV}$ in non-shocked mice).

This increase in AMPAR-mEPSC amplitudes may result from an increased surface expression of AMPARs, especially GluR1-containing AMPARs (O'Brien et al, 1998). Therefore, we quantified GluR1 protein levels in the synaptosomal membrane fraction of dissected DG tissue of shocked $v s$ non-shocked WT (ie, C57BL/6N) mice by western blot. Exposure to foot shock led to a significant increase in surface expression of GluR1 in the DG as assessed 28 days later (Figure 3b). A more detailed temporal analysis of 

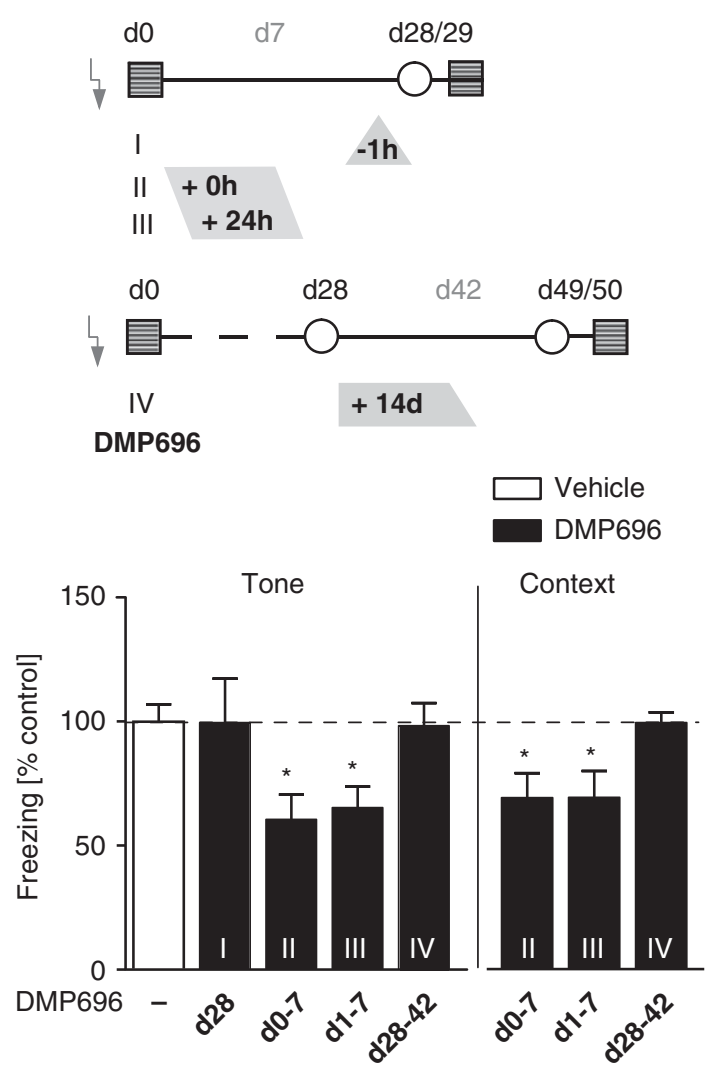

Figure 2 Effects of the CRHRI antagonist DMP696 on development, expression, and retention of remote fear memories. Treatment with the CRHRI antagonist DMP696 (3 mg/kg, p.o.) at different time points after foot shock affects consolidation, but not expression and retention of sensitized and contextual fear. Group I, acute drug administration before neutral tone exposure at day 28 after the shock ( $($ vehicle/DMP696) $=121$ 13); group II, immediate post-foot shock drug treatment lasting for 7 days (twice daily; $n=14 / / 3$ ); group III, delayed post-foot shock ( + 24h) drug treatment lasting for 7 days (twice daily; $n=14 / 13$ ) and testing on day 28/29; group IV, therapeutic treatment starting 28 days after the foot shock and lasting for 2 weeks (twice daily; $n=16 / 16$ ) followed by a wash-out period of I week before testing on day 49/50. Freezing data of DMP696treated mice were expressed as a percentage of the averaged freezing responses of the respective vehicle-treated controls (dashed line $=100 \%$ ). ${ }^{*} p<0.05$ (one-sample $t$-test).

GluR1 expression revealed wave-like changes in synaptosomal GluR1-containing AMPARs with peak levels $1 \mathrm{~h}$ and 28 days and a trough 3 days after foot shock (Figure $3 b$ ). In contrast, total DG GluR1 or GluR2 levels did not differ significantly between shock or non-shock groups 28 days after delivery of the foot shock, as measured in a separate experiment (GluR1 (\% normalized to controls): $116.3 \pm 7.7 \%, p=0.07$ (one-sample $t$-test); GluR2 (\% normalized to controls), $89.5 \pm 5.7 \%, p=0.11$ (one-sample $t$-test); $n=8-9$ per group).

\section{GluR1-Containing AMPARs in the Hippocampus Contribute to Retrieval and/or Expression of Remote Fear Memories}

The involvement of the hippocampus in storage and/or retrieval of remote contextual and episodic-like memories is still a matter of debate (Kim and Fanselow, 1992; Kitamura a
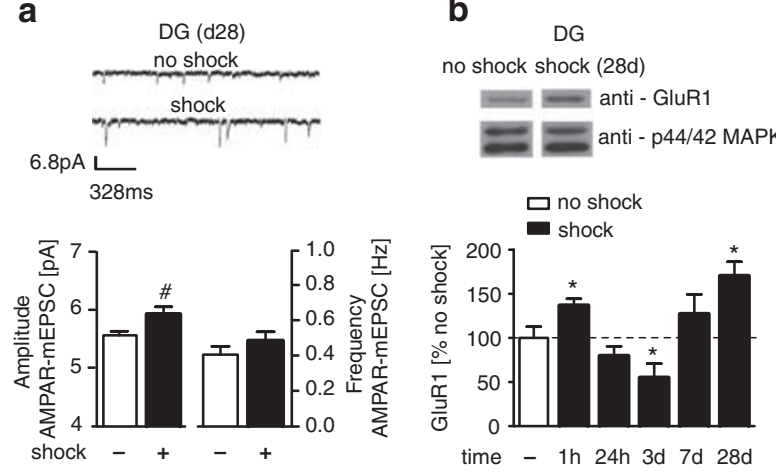

C

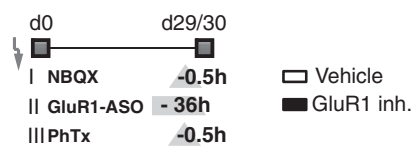

d
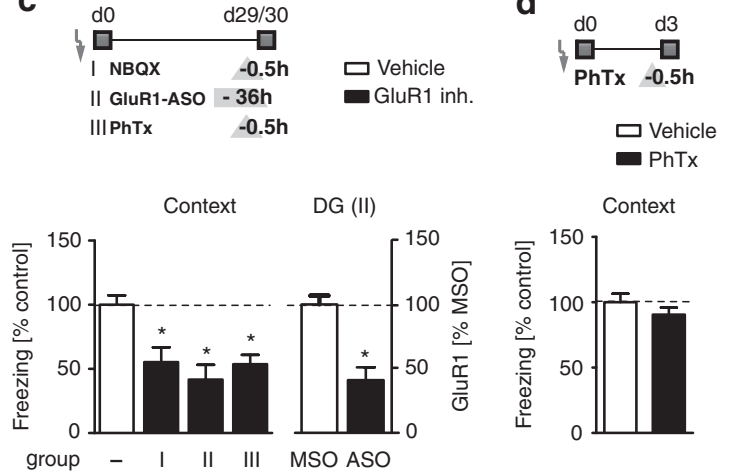

Figure 3 Hippocampal GluRI-containing AMPARs control the retention and/or expression of remote fear. (a) Representative traces of in vitro patch-clamp AMPAR-mEPSC recordings from DG granule cells of C57BL/ $6 \mathrm{~N}$ mice 28 days after exposure to a foot shock or control exposure (upper panel). Shocked mice showed significantly increased amplitudes, but not frequencies, of AMPAR-mEPSCs ( $N$ (no shock/shock) $=7 / 12$ mice; $n$ (no shock/shock) =20/29 neurons). (b) Western blot analyses of synaptosomal GluRI protein in the DG of C57BL/6N mice I h, $24 \mathrm{~h}, 3$ days, 7 days, or 28 days after exposure to a foot shock or control exposure (controls for early group ( $\mathrm{h}$ to 7 days) and separate controls for the 28-day group). Shocked mice showed significantly higher levels of membrane-standing GluRI at time points I h and 28 days and significantly lower levels 3 days after foot shock (shock: $n=6$ ( 1 h, 24 h, 3 days, 7 days) and 10 (28 days) per group; no shock: $n=6$ per early group, $n=10$ per 28-day group). (c) Left: Attenuated AMPAR signaling in the dorsal hippocampus of C57BL/6N mice significantly reduced contextual fear I month after conditioning. Group I, acute infusion of NBQX $(50 \mu \mathrm{M}$; $n=\mid \mathrm{I})$, an AMPA and kainate receptor antagonist; group II, infusion of GluRI antisense oligonucleotides (ASO $5 \mu \mathrm{M} ; n=7 ; 3$ infusions spaced $12 \mathrm{~h}$ apart); group III, acute treatment with philanthotoxin 433 (PhTx; I $00 \mu \mathrm{M} ; n=13)$, a specific antagonist of $\mathrm{Ca}^{2+}$-permeable GluRI-containing AMPA receptors. Controls received vehicle $(n=10-12)$ or GluRI missense oligonucleotides (MSO $5 \mu \mathrm{M} ; n=6$ ). Right: Western blot analysis revealed that GluRI ASO significantly reduced total GluRI in the dentate gyrus of group II mice compared with MSO-treated controls. (d) Acute infusions of $\operatorname{PhTx}(100 \mu \mathrm{M} ; n=10)$ into the hippocampus before contextual fear testing on day 3 after conditioning did not affect the fear response compared with vehicle-treated controls $(n=1 \mathrm{I})$. GluRI/MAPK ratios (panel b) and freezing data (panel c) were expressed as a percentage of the means of the respective controls (dashed line $=100 \%$ ). ${ }^{\#} p<0.05$ (unpaired $t$-test), ${ }^{*} p<0.05$ (one-sample $t$-test compared with control levels of 100\%).

et al, 2009; Pastalkova et al, 2006; Wiltgen et al, 2010; Winocur et al, 2010). Therefore, we confirmed the physiological relevance of hippocampal GluR1 receptors for remote contextual fear memories by various means: First, an acute pharmacological blockade of hippocampal AMPA and kainate receptors by NBQX significantly reduced 
contextual fear 29 days after conditioning (group I, Figure $3 c ; \quad t_{19}=2.5 ; \quad p=0.021$; control freezing: $53.0 \pm 7.2 \%)$. Second, reduced remote contextual fear was observed after inhibition of GluR1 synthesis by locally infused ASOs (group II) as compared with MSO treatment (Figure $3 c$, left; $t_{11}=2.3 ; p=0.043$; control freezing: $52.0 \pm 12.6 \%)$. Western blot analysis confirmed that ASO treatment led to significantly reduced total GluR1 protein levels in the DG of the dorsal hippocampus $\left(t_{11}=4.7\right.$; $p<0.001$; Figure $3 c$, right). Third, intrahippocampal administration of philanthotoxin 433 (PhTx), a specific blocker of $\mathrm{Ca}^{2+}$-permeable GluR1-containing AMPARs, also reduced context freezing in the long-term aftermath of the trauma (group III, Figure 3c, left; $t_{23}=4.7 ; p<0.001$; control freezing: $69.3 \pm 4.6 \%$ ). It is noteworthy that, as revealed in new groups of mice, the same treatment had no effects on contextual fear 3 days after the foot shock (Figure $3 \mathrm{~d}$; $t_{19}=1.1 ; p=0.284$; control freezing: $64.6 \pm 4.3 \%$ ).

Taken together, these findings demonstrate that $\mathrm{Ca}^{2+}$ permeable GluR1-containing AMPARs of the hippocampus have a prominent role in the retention and/or expression of remote fear memories.

\section{Limbic CRHR1 Affects Remote Fear Memories through Changing the Expression of GluR1-Containing AMPARs}

Finally, we looked for potential interactions between CRHR1 signaling and the expression of GluR1-containing AMPARs. In accordance with our observations in C57BL/6N mice (cf. Figure 3a), R1 ${ }^{\text {CaMKII }}$ WT showed a significant increase in the amplitudes of AMPAR-mEPSCs in DG granule cells 28 days after foot shock, compared with nonshocked WT controls (Figure $4 \mathrm{a} ; t_{41}=2.2 ; p=0.036$ ). $\mathrm{R} 1^{\text {CaMKII }} \mathrm{KO}$, in contrast, failed to show similar changes. Consequently, the increase in the amplitudes observed in shocked WT mice was significantly higher than that of shocked KO (Figure 4a; $t_{44}=2.6 ; p=0.011$; DG neuron RMPs: $\mathrm{RMP}_{\mathrm{WT}}$, no shock: $54.6 \pm 2.0 \mathrm{mV}, \mathrm{RMP}_{\mathrm{KO}}$, no shock: $56.3 \pm 1.9 \mathrm{mV}$; shock: $\mathrm{RMP}_{\mathrm{WT}}$, shock $54.8 \pm 1.7 \mathrm{mV}, \mathrm{RMP}_{\mathrm{KO}}$, shock: $53.1 \pm 1.5 \mathrm{mV})$.

Shocked R1 ${ }^{\text {CaMKII }}$ KO mice also expressed significantly less surface GluR1 protein in the DG than did shocked $\mathrm{R} 1^{\text {CaMKII }} \mathrm{WT}$ (as measured by western blots in synaptosomal membrane preparations of dissected DG tissue in the remote fear situation; Figure $\left.4 \mathrm{~b} ; t_{8}=2.5 ; p=0.036\right)$. No genotype differences were observed under non-shock conditions (data not shown). Similarly, WT mice treated with DMP696 for 1 week starting $24 \mathrm{~h}$ after foot shock (cf. group III, Figure 2) also showed reduced synaptosomal GluR1 levels than did shocked vehicle-treated controls (Figure $4 c ; t_{8}=3.7 ; p=0.007$ ). In addition, there was a significant positive correlation between the contextual fear responses shown at day 28 and the levels of GluR1 in vehicle and DMP696-treated mice (Figure 4d; Pearson's $r=0.71$; $p=0.03)$.

Taken together, these findings indicate that pharmacological blockade of CRHR1 within the first week after conditioning interferes with the consolidation of remote fear memories by preventing the long-lasting increase in GluR1-mediated neurotransmission at the level of the DG. b

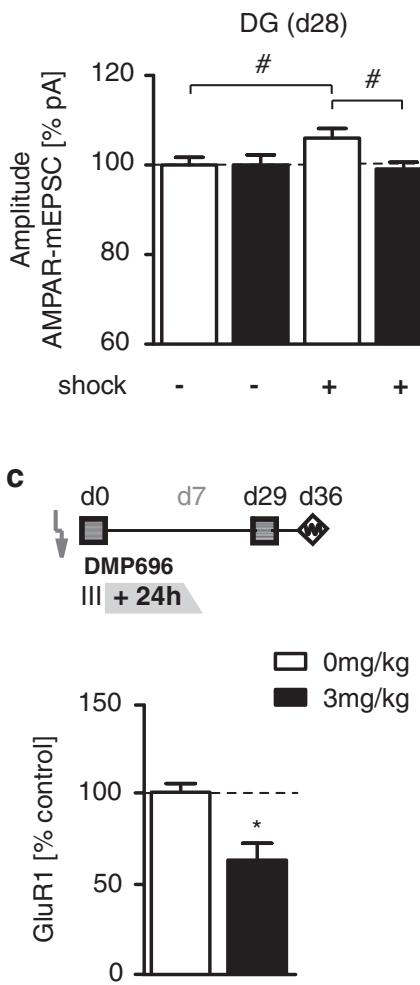

d
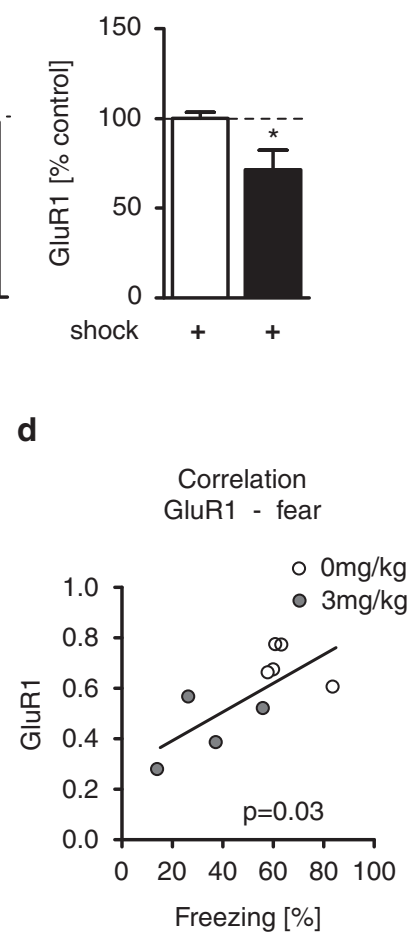

Figure 4 Hippocampal AMPAR neurotransmission is controlled by limbic CRHRI. (a) Amplitudes of AMPAR-mEPSCs were significantly increased in DG granule cells of wild-type littermate controls, but not in $\mathrm{RI}^{\mathrm{CaMKII}} \mathrm{KO}$ s, 28 days after conditioning as compared with shocked KO and non-shocked WT. Sample sizes were as follows: $n_{\text {no shock (control/ }}$ $\mathrm{RI}^{\mathrm{CaMKII}} \mathrm{KO}$ ) $=20 / 20, n_{\text {shock }}=23 / 23$ neurons measured in $N_{\text {no shock }}$ (control/RI CaMKII $\mathrm{KO}$ ) $=6 / 7$ and $N_{\text {shock }}=7 / 8$ mice. (b) RI CaMKII $\mathrm{KO}$ displayed significantly less synaptosomal GluRI protein levels in the DG than did littermate WT controls 28 days after foot shock ( $n=5$ per group). (c) DMP696 treatment starting $24 \mathrm{~h}$ after trauma and lasting for 7 days (cf. Figure 2, group III) led to significantly reduced surface expression of GluR I in the DG 36 days after foot shock, compared with vehicle-treated controls ( $n=5$ per vehicle, $n=4$ per DMP696). (d) Significant positive correlation of GluRI and freezing levels in DMP696 and vehicle-treated mice (cf. group III; Figure 2). AMPAR-mEPSC data were expressed relative to the nonshock levels of the same genotype; GluRI/MAPK ratios were expressed as a percentage of the mean WT levels. ${ }^{\#} p<0.05$ (unpaired $t$-test), ${ }^{*} p<0.05$ (one-sample t-test).

\section{DISCUSSION}

This study demonstrates by genetic and pharmacological means that $\mathrm{CRH}$ enhances the consolidation, but does not affect expression or retention, of remote fear memories (ie, freezing to context) and fear sensitization (ie, freezing to neutral tone), and that this effect depends on CRHR1 signaling in the limbic forebrain within the first week after perception of an aversive foot shock. It has already been reported that $\mathrm{CRH}$ facilitates the acquisition and consolidation of fear memories, as assessed within a few days after conditioning (Kolber et al, 2008; Pitts et al, 2009; Radulovic et al, 1999; Roozendaal et al, 2002). Our data substantially extend these observations by demonstrating that CRHR1 signaling has a pivotal role in the consolidation of remote 
fear memories. In fact, conditional mutants lacking CRHR1 expression in the limbic forebrain ( $\left.\mathrm{R} 1^{\mathrm{CaMKII}} \mathrm{KO}\right)$ showed significantly less sensitized and contextual fear 1 month, but not a few days, after delivery of the foot shock. In line with this reasoning, transient pharmacological blockade of CRHR1 attenuated remote fear memories even if initiated $24 \mathrm{~h}$ after foot shock, ie, after the initial consolidation period.

In a number of subsequent experiments, we identified and characterized GluR1-containing AMPARs within the dorsal hippocampus as putative effectors of CRHR1-mediated consolidation of remote fear memories. Learning-induced expression and trafficking of this specific glutamate receptor subtype in the hippocampus or amygdala have consistently been shown to be required for the consolidation of context (Matsuo et al, 2008; Mitsushima et al, 2011) and auditory fear memory (Hu et al, 2007; Rumpel et al, 2005; Thoeringer et al, 2010) and inhibitory avoidance learning (Cammarota et al, 2004; Whitlock et al, 2006). These studies investigated GluR1-driven consolidation mechanisms at early time points after conditioning leaving the question about the role of hippocampal AMPAR regulation in the development and stabilization of long-lasting memories unanswered. In this study, we observed a so far unrecognized delayed-onset and long-lasting increase in AMPAR GluR1-mediated neurotransmission in the DG, which became evident by increased amplitudes of AMPAR-mEPSCs and increased GluR1 surface expression in synaptosomal fractions. GluR1 expression peaked $1 \mathrm{~h}$ and 28 days after foot shock, but showed a trough after 3 days. Consequently, GluR1-containing AMPARs might be involved not only in acquisition and initial consolidation of fear but also, and in particular, in the retention/expression of remote fear memories. This conclusion was substantiated by the finding that both pharmacological blockade and ASO-mediated downregulation of GluR1-containing AMPARs attenuated remote contextual fear. A similar result has recently been published for the retrieval of detailed contextual memories in mice (Wiltgen et al, 2010). It is noteworthy that treatment with philanthotoxin 433 attenuated contextual fear 29 days, but not 3 days, after conditioning, thus substantiating that $\mathrm{Ca}^{2+}$-permeable GluR1-containing AMPARs have a prominent role in the retention and/or expression of remote fear memories. As these effects were abolished in R1 CaMKII KO and CRHR1 antagonist-treated mice, we conclude that $\mathrm{CRH}$ enhances the consolidation of remote fear memories by stabilizing the surface expression of GluR1-containing AMPARs.

It is still a matter of debate whether episodic and contextual memories are permanently stored in the hippocampus. Our study proves a major role of the dorsal hippocampus in the expression and/or retention of remote fear memories 1 month after conditioning. In this manner, it contradicts the hypothesis of a temporally limited involvement of the hippocampus in memory storage and/ or recall (Kim and Fanselow, 1992). It is conceivable that differences in the involvement of the hippocampus in recall/ expression of remote fear memories relate, at least in part, to the intensity of the conditioning procedure used in this study $(1.5 \mathrm{~mA})$ : Higher emotional load (stress) is associated with decreased neurogenesis at the level of the DG (Dranovsky and Hen, 2006) that, in turn, may account for the persistent involvement of the hippocampus in processing of remote fear memories (Kitamura et al, 2009). An enhanced postsynaptic AMPAR neurotransmission within the DG may contribute to this process and, thus, accompany recurrent activation of NMDA receptors (Shimizu et al, 2000) as mediator of long-term retention of remote fear memories.

In the clinical situation, exaggerated remote fear memories and hyperarousal (ie, fear sensitization) are core symptoms of PTSD. Given the fact that PTSD patients show elevated cerebrospinal fluid levels of CRH (Baker et al, 1999; Bremner et al, 1997), our findings provide the neurobiological rationale for a pharmacological blockade of CRHR1 in the early aftermath of a trauma as a novel treatment strategy for attenuating the development of the disease. Despite potential side effects (Holsboer and Ising, 2010), treatment with CRHR1 antagonist might be a more promising approach than, eg, the $\beta$-blocker propranolol (so far the only drug extensively tested in the pharmaco-prophylaxis of PTSD), which has failed to meet initial hopes (Baker et al, 2009). Importantly, CRHR1 antagonist treatment might be initiated even $24 \mathrm{~h}$ after the traumatic incident and discontinued after a few days, thus demonstrating a sufficiently broad temporal window for pharmacological intervention, while minimizing the risk of potential side effects.

\section{ACKNOWLEDGEMENTS}

We thank A Siegmund for helpful comments on concept and implementation of the study and $\mathrm{C}$ Riebe for her comments on the manuscript. We also thank A Mederer, $\mathrm{U}$ Habersetzer, A Jurik, A Baumgartner, S Meyr, R Menz, and $S$ Unkmeir for expert technical assistance. This work was partially supported by AGNP (CKT), the Bundesministerium für Bildung und Forschung within the framework of the NGFN-Plus (FKZ: 01GS08151 and 01GS08155; JMD and WW) and by the Initiative and Networking Fund of the Helmholtz Association in the framework of the Helmholtz Alliance for Mental Health in an Ageing Society (HA-215; JMD and WW).

\section{DISCLOSURE}

The authors declare no conflict of interest.

\section{REFERENCES}

Adamec R, Fougere D, Risbrough V (2010). CRF receptor blockade prevents initiation and consolidation of stress effect on affect in the predator stress model of PTSD. Int J Neuropsychopharmacol 13: 747-757.

Albucher RC, Liberzon I (2002). Psychopharmacological treatment in PTSD: a critical review. J Psychiatr Res 36: 355-367.

Baker DG, Nievergelt CM, Risbrough VB (2009). Posttraumatic stress disorder: emerging concepts of pharmacotherapy. Expert Opin Emerg Drugs 14: 251-272.

Baker DG, West SA, Nicholson WE, Ekhator NN, Kasckow HW, Hill KK et al (1999). Serial CSF corticotropin-releasing hormone levels and adrenocortical activity in combat veterans with posttraumatic stress disorder. Am J Psychiatry 156: 585-588. 
Bale TL, Vale WW (2004). CRF and CRF receptors: role in stress responsitivity and other behaviors. Annu Rev Pharmacol Toxicol 44: 525-557.

Bekinschtein P, Cammarota M, Igaz LM, Bevilaqua LR, Izquierdo I, Medina JH (2007). Persistence of long-term memory storage requires a late protein synthesis- and BDNF-dependent phase in the hippocampus. Neuron 53: 261-277.

Bremner JD, Licinio J, Darnell A, Krystal JH, Owens MJ, Southwick SM et al (1997). Elevated CSF corticotropin-releasing factor concentration in posttraumatic stress disorder. Am J Psychiatry 154: 624-629.

Cammarota M, Bevilaqua LR, Bonini JS, Rossatto JI, Medina JH, Izquierdo $N$ (2004). Hippocampal glutamate receptors in fear memory consolidation. Neurotox Res 6: 205-212.

Clem RL, Huganir RL (2010). Calcium-permeable AMPA receptor dynamics mediate fear memory erasure. Science 330: 1108-1112.

Coste SC, Kesterson RA, Heldwein KA, Stevens SL, Heard AD, Hollis $\mathrm{JH}$ et al (2000). Abnormal adaptations to stress and impaired cardiovascular function in mice lacking corticotropinreleasing hormone receptor-2. Nat Genet 24: 403-409.

Cui Z, Wang H, Tan Y, Zaia KA, Zhang S, Tsien JZ (2004). Inducible and reversible NR1 knockout reveals crucial role of the NMDA receptor in preserving remote memories in the brain. Neuron 41: 781-793.

Dahlhoff M, Siegmund A, Golub Y, Wolf E, Holsboer F, Wotjak CT (2010). AKT/GSK3beta/beta-catenin signalling within hippocampus and amygdale reflects genetically determined differences in posttraumatic stress disorder like symptoms. Neuroscience 169: 1216-1226.

Dranovsky A, Hen R (2006). Hippocampal neurogenesis: regulation by stress and antidepressants. Biol Psychiatry 59: 1136-1143.

Frankland PW, Bontempi B, Talton LE, Kaczmarek L, Silva AJ (2004). The involvement of the anterior cingulate cortex in remote contextual fear memory. Science 304: 881-883.

Franklin KBJ, Paxinos G (2001). The Mouse in Stereotaxic Coordinates. Academic Press: San Diego.

Golub Y, Mauch CP, Dahlhoff M, Wotjak CT (2009). Consequences of extinction training on associative and non-associative fear in a mouse model of Posttraumatic Stress Disorder (PTSD). Behav Brain Res 205: 544-549.

Holsboer F, Ising M (2010). Stress hormone regulation: biological role and translation into therapy. Annu Rev Psychol 61: 81-109.

$\mathrm{Hu} \mathrm{H}$, Real E, Takamiya K, Kang MG, Ledoux J, Huganir RL et al (2007). Emotion enhances learning via norepinephrine regulation of AMPA-receptor trafficking. Cell 131: 160-173.

Kamprath K, Wotjak CT (2004). Nonassociative learning processes determine expression and extinction of conditioned fear in mice. Learn Mem 11: 770-786.

Kessler RC, Sonnega A, Bromet E, Hughes M, Nelson CB (1995). Posttraumatic stress disorder in the National Comorbidity Survey. Arch Gen Psychiatry 52: 1048-1060.

Kim JJ, Fanselow MS (1992). Modality-specific retrograde amnesia of fear. Science 256: 675-677.

Kitamura T, Saitoh Y, Takashima N, Murayama A, Niibori Y, Ageta $\mathrm{H}$ et al (2009). Adult neurogenesis modulates the hippocampus-dependent period of associative fear memory. Cell 139: 814-827.

Kolber BJ, Roberts MS, Howell MP, Wozniak DF, Sands MS, Muglia LJ (2008). Central amygdala glucocorticoid receptor action promotes fear-associated CRH activation and conditioning. Proc Natl Acad Sci USA 105: 12004-12009.

Li YW, Hill G, Kelly N, Ward K, Pierdomenico M, Ren S et al (2003). Receptor occupancy of nonpeptide corticotropin-releasing factor 1 antagonist DMP696: correlation with drug exposure and anxiolytic efficacy. J Pharmacol Exp Ther 305: $86-96$.
Matsuo N, Reijmers L, Mayford M (2008). Spine-type-specific recruitment of newly synthesized AMPA receptors with learning. Science 319: 1104-1107.

Mitsushima D, Ishihara K, Sano A, Kessels HW, Takahashi T (2011). Contextual learning requires synaptic AMPA receptor delivery in the hippocampus. Proc Natl Acad Sci USA 108: 12503-12508.

Müller MB, Zimmermann S, Sillaber I, Hagemeyer TP, Deussing JM, Timpl P et al (2003). Limbic corticotropin-releasing hormone receptor 1 mediates anxiety-related behavior and hormonal adaptation to stress. Nat Neurosci 10: 1100-1107.

O'Brien RJ, Kamboj S, Ehlers MD, Rosen KR, Fischbach GD, Huganir RL (1998). Activity-dependent modulation of synaptic AMPA receptor accumulation. Neuron 21: 1067-1078.

Pamplona FA, Henes K, Micale V, Mauch CP, Takahashi RN, Wotjak CT (2011). Prolonged fear incubation leads to generalized avoidance behavior in mice. J Psychiatr Res 45: 354-360.

Pastalkova E, Serrano P, Pinkhasova D, Wallace E, Fenton AA, Sacktor TC (2006). Storage of spatial information by the maintenance mechanism of LTP. Science 313: 1141-1144.

Peri T, Ben-Shakhar G, Orr SP, Shalev AY (2000). Psychophysiologic assessment of aversive conditioning in posttraumatic stress disorder. Biol Psychiatry 47: 512-519.

Pitts MW, Todorovic C, Blank T, Takahashi LK (2009). The central nucleus of the amygdala and corticotropin-releasing factor: insights into contextual fear memory. J Neurosci 29: 7379-7388.

Ressler KJ, Mercer KB, Bradley B, Jovanovic T, Mahan A, Kerley K et al (2011). Post-traumatic stress disorder is associated with PACAP and the PAC1 receptor. Nature 24: 492-497.

Roozendaal B, Brunson KL, Holloway BL, McGaugh JL, Baram TZ (2002). Involvement of stress-related corticotropin-releasing hormone in the basolateral amygdala in regulating memory consolidation. Proc Natl Acad Sci USA 99: 13908-13913.

Radulovic J, Rühmann A, Liepold T, Spiess J (1999). Modulation of learning and anxiety by corticotropin-releasing factor (CRF) and stress: differential roles of CRF receptors 1 and 2. J Neurosci 19: 5016-5025.

Rumpel S, LeDoux J, Zador A, Malinow R (2005). Postsynaptic receptor trafficking underlying a form of associative learning. Science 308: 83-88.

Sahay A, Wilson DA, Hen R (2011). Pattern separation: a common function for new neurons in hippocampus and olfactory bulb. Neuron 70: 582-588.

Schmidt MV, Deussing JM, Oitzl MS, Ohl F, Levine S, Wurst W et al (2006). Differential disinhibition of the neonatal hypothalamic-pituitary-adrenal axis in brain-specific CRH receptor 1knockout mice. Eur J Neurosci 24: 2291-2298.

Shimizu E, Tang YP, Rampon C, Tsien JZ (2000). NMDA receptordependent synaptic reinforcement as a crucial process for memory consolidation. Science 290: 1170-1174.

Siegmund A, Wotjak CT (2006). Toward an animal model of posttraumatic stress disorder. Ann N Y Acad Sci 1071: 324-334.

Siegmund A, Wotjak CT (2007). A mouse model of posttraumatic stress disorder that distinguishes between conditioned and sensitised fear. J Psychiatr Res 41: 848-860.

Slipczuk L, Bekinschtein P, Katche C, Cammarota M, Izquierdo I, Medina JH (2009). BDNF activates mTOR to regulate GluR1 expression required for memory consolidation. PLOS One 4: e6007.

Thoeringer CK, Pfeiffer UJ, Rammes G, Pamplona FA, Moosmang S, Wotjak CT (2010). Early life environment determines the development of adult phobic-like fear responses in BALB/cAnN mice. Gene Brain Behav 9: 947-957.

Timpl P, Spanagel R, Sillaber I, Kresse A, Reul JM, Stalla GK et al (1998). Impaired stress response and reduced anxiety in mice lacking a functional corticotropin-releasing hormone receptor 1. Nat Genet 19: 162-166. 
Tovote P, Meyer M, Ronnenberg A, Ogren SO, Spiess J, Stiedl O (2005). Heart rate dynamics and behavioral responses during acute emotional challenge in corticotropin-releasing factor receptor 1-deficient and corticotropin-releasing factor-overexpressing mice. Neuroscience 134: 1113-1122.

Treves A, Tashiro A, Witter ME, Moser EI (2008). What is the mammalian dentate gyrus good for? Neuroscience 154: 1155-1172.

Vale W, Spiess J, Rivier C, Rivier J (1981). Characterization of a 41residue ovine hypothalamic peptide that stimulates secretion of corticotropin and beta-endorphin. Science 213: 1394-1397.

Walker DL, Toufexis DJ, Davis M (2003). Role of the bed nucleus of the stria terminalis versus the amygdale in fear, stress, and anxiety. Eur J Pharmacol 463: 199-216.
Whitlock JR, Heynen AJ, Shuler MG, Bear MF (2006). Learning induces long-term potentiation in the hippocampus. Science 313: 1093-1097.

Wiltgen BJ, Zhou M, Cai Y, Balaji J, Karlsson MG, Parivash SN et al (2010). The hippocampus plays a selective role in the retrieval of detailed contextual memories. Curr Biol 20: 1336-1344.

Winocur G, Moscovitch M, Bontempi B (2010). Memory formation and long-term retention in humans and animals: convergence towards a transformation account of hippocampal-neocortical interactions. Neuropsychologica 48: 2339-2356.

Yehuda R, LeDoux J (2007). Response variation following trauma: a translational neuroscience approach to understanding PTSD. Neuron 56: 19-32. 